ЛАТЕНТНАЯ АСИММЕТРИЯ СИСТЕМНОЙ ОРГАНИЗАЦИИ ПЛЕЧЕВОЙ КОСТИ ДОМАШНЕГО БЫКА (BOS TAURUS) КАК СВИДЕТЕЛЬСТВО МОРФОФУНКЦИОНАЛЬНОЙ ДИФФЕРЕНЦИАЦИИ КОСТЕЙ КОНЕЧНОСТЕЙ МЛЕКОПИТАЮЩИХ ЖИВОТНЫХ

1Яшина И.Н. , 1 Иванов А.В. , ${ }^{2}$ Клочкова С.В.

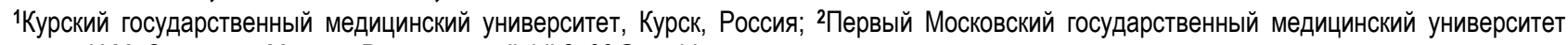
имени И.М. Сеченова, Москва, Россия, e-mail: bik2709@rambler.ru

\title{
THE LATENT ASYMMETRY OF THE SYSTEMIC ORGANIZATION OF THE HUMERUS OF THE DOMESTIC BULL (BOS TAURUS) AS EVIDENCE OF THE MORPHOLOGICAL-FUNCTIONAL DIFFERENTIATION OF THE BONES OF THE MAMMALIAN LIMBS
}

1Yashina IN, 1'Ivanov AV, ${ }^{2}$ Klochkova SV

${ }^{1}$ Kursk State Medical University, Kursk, Russia; ${ }^{2}$ Sechenov First Moscow State Medical University, Moscow, Russia, e-mail: bik2709@rambler.ru

Дия циитирования:

Яшина И.Н., Иванов А.В., Клочкова С.В. Латентная асимметрия системной организации плечевой кости домашнего быка (Воз Таитиз) как свидетельство морфо-функциональной дифференциации костей конечностей млекопитаюших животных// Морфологические ведомости.- 2019.- Том 27.- № 1.- С. 25-29. https://doi.org/10.20340/mv-mn.19(27).01.25-29

For the citation:

Yashina IN, Ivanov AV, Klochkova SV. The latent asymmetry of the systemic organization of the humerus of the domestic bull (Bos Taurus) as evidence of the morphological-functional differentiation of the bones of the mammalian limbs. Morfologicheskie Vedomosti - Morphological Newsletter. 2019 March 31; 27(1):25-29. https://doi.org/10.20340/mv-mn.19(27).01.25-29

Резюме: Различия в степени развития костей проксимального звена грудных конечностей связаны с особенностями биомеханики вида млекопитающего животного. Для Bovinae характерна симметричная локомоция. В сравнительноанатомическом аспекте представляет интерес выяснение асимметрии анатомических структур, обеспечивающих такой вид движения. Цель исследования - выяснение особенностей строения и системной организации плечевой кости крупных парнокопытных животных с дорсо-стабильным типом локомоции на примере домашнего быка. Представлены результаты исследования особенностей системной организации анатомических структур плечевой кости домашнего быка на основе измерения ее остеометрических показателей. На каждой кости 40 животных были измерены 29 структур. Значения линейных параметров были нормализованы, за единицу принят поперечный диаметр диафиза кости на середине ее длины. Далее отдельно в группе препаратов правой и левой сторон нормализованные значения линейных и угловых параметров были обработаны методом факторного анализа. Выявлено три фактора, влияющих на строение правой плечевой кости, четыре - на строение левой плечевой кости. Параметры, присутствующие в системной организации обоих костей, были определены как системно стабильные. Анализ структуры анатомической организации плечевой кости быка позволил выделить пять базовых системно стабильных параметров в структуре проксимального эпифиза, три - в структуре диафиза и восемь - в структуре дистального эпифиза. Параметры, присутствующие только в системной организации одной из костей и указывающие на асимметрию в выполнении функции, обозначены как системно нестабильные. Нестабильных параметров на уровне проксимального эпифиза выделено четыре, на уровне дистального - два. Асимметрия системной организации проявляется за счет разницы в реализации двигательной функции на уровнях эпифизов кости. В результате исследования выяснено, что ключевую роль в формировании системной организации плечевой кости играют базовые системно стабильные параметры, обеспечивающие трансляцию веса животного. Асимметрия системной организации проявляется за счет разницы в реализации двигательной функции на уровнях эпифизов кости, что указывает на морфофункциональную дифференциацию эпифизов млекопитающих животных, отражающую специфику типа движения.

Ключевые слова: структурная асимметрия, плечевая кость, конечности млекопитаюштх

Summary: Differences in the degree of development of the bones of the proximal part of the thoracic limbs are associated with the peculiarities of the biomechanics of the mammalian species. Symmetric locomotion is characteristic of Bovinae. In the comparative anatomical aspect, it is of interest to clarify the asymmetry of the anatomical structures that provide this kind of movement. The purpose of the study is the analyze the features of the structure and systemic organization of the humerus of large cloven-hoofed animals with a dorsostable type of locomotion using the example of a domestic bull. The results of a study of the features of the systemic organization of the anatomical structures of the humerus of the domestic bull based on the measurement of its osteometrical parameters are presented. On each bone of 40 animals, 29 structures were measured. The values of the linear parameters were normalized, the transverse diameter of the bone shaft in the middle of its length was taken as a unit. Further, separately in the group of drugs of the right and left sides, the normalized values of linear and angular parameters were processed by the method of factor analysis. Three factors have been identified that affect the structure of the right humerus, four - on the structure of the left humerus. The parameters present in the system organization of both bones were identified as systemically stable. Analysis of the structure of the anatomical organization of the humerus of the bull allowed to identify five basic systemically stable parameters in the structure of the proximal epiphysis, three in the structure of the diaphysis and eight in the structure of the distal epiphysis. Parameters that are present only in the system organization of one of the bones and indicate an asymmetry in the performance of the function are designated as systemically unstable. There are four unstable parameters at the level of the proximal epiphysis, two at the distal level. The asymmetry of the systemic organization is manifested due to the difference in the implementation of the motor function at the levels of the epiphyses of the bone. As a result of the study, it was found that the basic systemically stable parameters that ensure the transmission of animal weight play a key role in the formation of the systemic organization of the humerus. The asymmetry of systemic organization is manifested due to the difference in the realization of motor function at the levels of the epiphyses of the bone, which indicates the morphological and functional differentiation of the epiphyses of mammals, reflecting the specificity of the type of movement.

Key words: structural asymmetry, humerus, mammalian limbs

Введение. Сравнительная анатомия изучает закономерности строения и развития животных организмов и их органов в процессе эволюции от низших фрорм к высшим путем сопоставления животных различных систематических групп. Доказательства исторической преемственности живых существ, их эволюционного развития основываются на наличии 
общего плана строения органов и существовании родственных по происхождению органов. Конечности всех наземных позвоночных устроены гомологично. Согласно онтогенетическому пониманию гомологии они развиваются из одинаковых эмбриональных зачатков и выполняют схожие функции. При этом каждый вид в ходе эволюции приобрел характерные адаптации, позволяющие ему занять определенную экологическую нишу. Анатомические отличия в строении скелета большинства животных и человека, их связь с биомеханикой движений были изучены в первой половине двадцатого века. Эти исследования касались прежде всего изучения изменений в строении костей дистального отдела конечностей. Вопросы строения костей проксимального звена изучены не полностью. Различия в степени развития костей проксимального звена грудных конечностей связаны с особенностями биомеханики вида [1-2]. Для Bovinae характерна симметричная локомоция. При этом типе передвижения первой двигается задняя нога затем диагонально расположенная передняя. При ходьбе конечности переставляются в таком порядке, чтобы всегда сохранялась опора в виде треугольника, создаваемого тремя конечностями - появляется так называемый дорсо-стабильный ди-локомоторный тяжелый шаг. Для передней конечности бычьих в большей степени характерна поддерживающая роль [3-5]. Обращая внимание на особенности функционирования грудной конечности Bovinae, нельзя не остановиться на работе мышц во время передвижения. В момент выноса конечности вперед суставы сгибаются, при этом вес тела нивелируется и осуществляется только двигательная функция. В этот момент большую роль в осуществлении сгибания плечевого сустава играет комплекс мышц лопатки: mm. teres major, teres minor, deltoideus, а вращение внутрь обеспечивают m. latissimus dorsi и m. teres major. Сгибание локтевого сустава при выносе конечности вперед обеспечивает m. brachialis. Вращательные движения в локтевом суставе у быков отсутствуют, поскольку кости предплечья срослись, группа мышц-вращателей отсутствует. Сгибание расположенных ниже суставов происходит инерционно, за счет мышц, прикрепляющихся к надмыщелкам плечевой кости. Одновременно со сгибателями функционируют $\mathrm{m}$. brachiocephalicus, $\mathrm{m}$. coracobrachialis $и \mathrm{~m}$. pectoralis. Во время контакта с землей грудная конечность выполняет амортизационную функцию. Она обеспечивается специфической фрормой копыта, амортизацией суставных хрящей и связочного аппарата суставов, работой «замыкательного» аппарата мышц - натяжением сухожилий мышц путового сустава и суставов пальцев, работой $\mathrm{m}$. biceps brachii и $\mathrm{m}$. lacertus fibrosus на удержание плечевого сустава от сгибания (движения конечности кзади). Следующим этапом является движение разгибания суставов с перемещением тела вперед. Это движение обеспечивается работой m. supraspinatus и m. biceps. Локтевой сустав в момент разгибания толкает вперед плечевую кость и лопатку с туловищем. Данное движение обеспечивается сокращением m. triceps brachii, m. anconaeus и одновременным сокращением разгибателей запястья и пальцев [5-6]. В сравнительно-анатомическом аспекте представляет значительный интерес выяснение асимметрии анатомических структур, обеспечивающих такой вид движения.

Цель исследования - выяснение особенностей строения и системной организации плечевой кости крупных парнокопытных животных с дорсостабильным типом локомоции на примере домашнего быка (Bos Taurus).

Материалы и методы исследования. Материалом исследования явились мацерированные плечевые кости 40 животных, 40 правых и 40 левых плечевых костей. Настоящее исследование проведено с соблюдением этических норм в рамках действующих нормативных актов (протокол заседания секции доклинических исследований локальной этической комиссии Курского госмедуниверситета Минздрава России № 5 от 30 июня 2018 года). На первом этапе производилось остеометрическое исследование плечевых костей. По разработанной авторами методике на каждой плечевой кости были измерены 29 структур, характеризующих степень ее развития [7]. Для измерения структур, описывающих внешний вид костей, в работе использовались: устройство для измерений длинных трубчатых костей (патент C $12245101 \mathrm{RU}$ A 61 B 5/103), цифровой штангенциркуль и транспортир. Все измерения производились одним исследователем дважды, полученные средние значения заносились в электронные таблицы Microsoft Excel.

Все исследуемые структуры были разделены на группы, относящиеся к диасизу и к эпифизам костей. Параметры, измеряемые на проксимальном эпифизе были следующими: ШПЭ - ширина проксимального эпифиза - наибольшее расстояние между головкой и большим бугром; ØГС - сагиттальный диаметр головки или передне-задний размер головки, измеренный в горизонтальной плоскости; ØГВ - вертикальный диаметр головки или верхне-нижний размер головки, измеренный во фронтальной плоскости; ØШС - сагиттальный диаметр шейки или передне-задний размер шейки, измеренный в горизонтальной плоскости; ØШВ - вертикальный диаметр шейки - расстояние, измеренное между максимально удаленными верхней и нижней точками шейки кости; МБР - межбугорковое расстояние - расстояние между вершинами большого и малого бугров; ШМББ - ширина межбугорковой борозды - внутреннее расстояние между гребнями бугорков; ГМББ - глубина межбугорковой борозды - расстояние между дном и касательной линией, проведенной между гребнями бугорков; УХКГ - угол хрящевого края головки с диафизом (рис. 1).

Параметры, измеряемые на диафизе кости были следующими: Дг - наибольшая длина кости, измеренная между максимально удаленными точками на нижней поверхности медиального мыщелка и наивысшей точкой на головке; Дбб наибольшая длина кости, измеренная между максимально удаленными точками на нижней поверхности медиального мыщелка и наивысшей точкой на большом бугре; ØДп - поперечный диаметр диафиза - расстояние между боковыми точками на середине длины кости во фронтальной плоскости; ØДс - сагиттальный диаметр диафиза - передне-заднее расстояние, измеренное на середине длины кости; УНД - угол наклона оси диафиза по отношению к перпендикуляру, восстановленному от горизонтальной плоскости мыщелков; УСК - угол скрученности плечевой кости или торсионной деформации диафиза, измерен между горизонтальными осью головки и шейки и межмыщелковой осью.

Параметры, измеряемые на дистальном эпифизе были слеждующими: ШдЭ - ширина дистального эпифиза наибольшее расстояние между надмыщелками; ШЛокЯ - ширина локтевой ямки - внутреннее расстояние между краями надмыщелков; ВЛокЯ - высота локтевой ямки, расстояние между горизонтальной линией, соединяющей края надмыщелков и границей локтевой ямки; ØГчкиВ - вертикальный диаметр головочки - измеряется между нижней и верхней точками суставной поверхности головочки при виде спереди; ШГчки - ширина суставной поверхности головочки, ограниченная латеральным гребнем, измеренная на середине высоты передней поверхности мыщелка; ВØЛГБ - вертикальный диаметр 
латерального гребня блока - измеряется между нижней и верхней точками латерального гребня блока при виде спереди; ШЛЧБ - ширина латеральной части суставной поверхности блока; СØлГБ - сагиттальный диаметр латерального гребня блока плечевой кости; ВØМГБ - вертикальный диаметр медиального гребня блока - измеряется между нижней и верхней точками медиального гребня блока при виде спереди; ШМЧБ - ширина медиальной части суставной поверхности блока; СØМГБ - сагиттальный диаметр медиального гребня блока; ШМНМ - ширина медиального надмыщелка - расстояние, измеренное горизонтально от максимально выступающей точки надмыщелка до края суставной поверхности; ШЛнМ ширина латерального надмыщелка - расстояние, измеренное горизонтально от максимально выступающей точки надмыщелка до края суставной поверхности; УНББ - угол направляющей борозды блока, измеренный между фрронтальной плоскостью позади мыщелка плеча и бороздой при виде снизу (рис. 1).

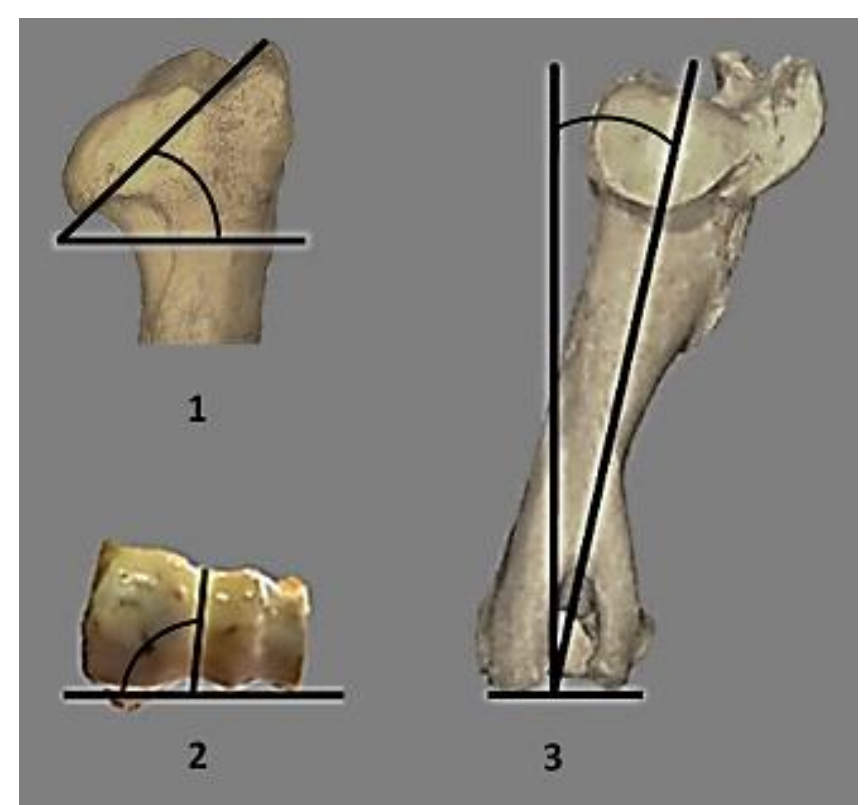

Рис. 1. Методика измерения угловых параметров на плечевой кости быка: 1 - угол покрытия головки суставным хрящом, 2 угол направляющей борозды блока, 3 - угол наклона оси диафиза.

компонент внутри каждого фрактора между собой буде выше, чем их коррелированность с компонентами из других факторов. Благодаря этому, отдельный фактор можно рассматривать как совокупность наиболее сильно взаимосвязанных между собой исходных признаков. Сила

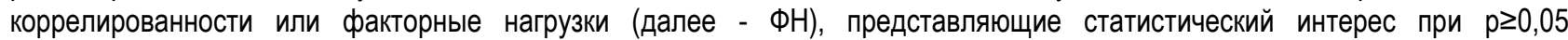
располагаются в диапазоне |0,7-1,0|. Все требования к выборкам для проведения факторного анализа были выполнены. В качестве корреляционной матрицы использовалась матрица корреляций Спирмена.

Результаты исследования и обсуждение. Поскольку методологически алгоритмическая схема реализации метода максимального правдоподобия включает последовательное выделение латентных фракторов с объяснением наибольшей доли дисперсии исходных переменных, процесс выделения факторов был прерван на уровне отсутствия изменений в картине факторных нагрузок и их дисперсий при увеличении числа факторов. Для плечевых костей быка картина изменения факторных нагрузок на исследуемые параметры и их дисперсий прекратились при выделении четырех факторов. Полученные данные представлены в таблице 1. Выделение факторов, влияющих на строение правой плечевой кости, остановилось на уровне трех. Картина факторных нагрузок при исследовании левой плечевой кости перестала изменяться при выделении четырех факторов системной организации. В результате проведенного анализа выяснено, что организация плечевой кости быков асимметрична, при этом методами описательной вариационной статистики различия в размерах костей не выявляются. Такая особенность может быть связана с наличием диагональной локомоции у данного вида животных и функциональной связью между двигательной активной правой задней конечностью и расположенной по диагонали левой грудной конечностью [6].

При этом в организации плечевой кости выделена группа параметров, формирующих факторы, или уровни системной организации кости независимо от принадлежности к стороне тела. Такие параметры были определены как системно стабильные. На наш взгляд, они являются базовыми при формировании системной организации кости. Это 9 параметров, имеющих практически равное значение факторных нагрузок. Ими явились размеры шейки, длины кости, вертикальные размеры частей дистального эпифиза, ширина дистального эпифиза и ширина медиальной части блока. Перечисленные параметры принимают участие в трансляции веса животного на нижележащие отделы конечности. Симметричные $Ф \mathrm{H}$ на структуры латерального разгибательного надмыщелка подтверждают стабилизирующую роль мышц разгибателей в запирании локтевого сустава при принятии веса на конечность. Отрицательные фракторные нагрузки, оказываемые углом наклона диафиза, указывают на ограничение данной функции при нарушении оси конечности.

Асимметричность организации плечевых костей проявляется не только разным числом уровней системной организации, но и разностью величин ФН. Среди системно стабильных параметров эту группу составили: ширина 
проксимального эпифиза, вертикальный размер головки, межбугорковое расстояние. Они опосредованно обеспечивают движения в плечевом суставе и указывают на присутствующую функциональную дифференциацию передних конечностей у животных. Межбугорковое расстояние отражает степень развития большого и малого бугорков. К большому бугорку прикрепляется $\mathrm{m}$. pectoralis profundus, приводящая конечность и сгибающая плечевой сустав. У основания tuberculum majus имеется площадка для прикрепления дистального сухожилия $\mathrm{m}$. infraspinatus $и \mathrm{~m}$. teres minor. M. infraspinatus отводит переднюю конечность в плечевом суставе и дополнительно выполняет функцию боковой связки сустава. M. teres minor сгибает и супинирует плечевой сустав. К малому бугорку прикрепляются $\mathrm{m}$. latissimus dorsi, crus mediale m. supraspinatus et m. subscapularis, выполняющие роль аддукторов плечевого сустава, и m. teres major, сгибающая и пронирующая плечевой сустав [5]. На уровне дистального эписиза асимметричные по силе ФН имеют ширина локтевой ямки и сагиттальный размер латерального гребня блока, определяющие амплитуду движений в локтевом суставе.

Факторные нагрузки остеометрических показателей плечевых костей домашнего быка Bos Taurus

Таблица 1

\begin{tabular}{|c|c|c|c|c|c|c|c|}
\hline \multirow{2}{*}{$\begin{array}{c}\text { Структура } \\
\text { факторных нагрузок }\end{array}$} & \multicolumn{3}{|c|}{ Правая плечевая кость } & \multicolumn{4}{|c|}{ Левая плечевая кость } \\
\hline & $\Phi 1^{*}$ & $\Phi 2$ & $\Phi 3$ & $\Phi 1$ & $\Phi 2$ & $\Phi 3$ & $\Phi 4$ \\
\hline ШПЭ & 0,75 & $-0,11$ & 0,16 & 0,87 & $-0,30$ & 0,06 & 0,27 \\
\hline$\varnothing Г г$ & 0,60 & $-0,13$ & $-0,14$ & 0,72 & $-0,11$ & 0,23 & $-0,38$ \\
\hline ØГв & 0,73 & $-0,28$ & $-0,17$ & 0,83 & $-0,21$ & $-0,20$ & 0,02 \\
\hline ØШг & 0,87 & 0,17 & 0,01 & 0,81 & 0,52 & $-0,16$ & 0,06 \\
\hline ØШв & 0,80 & $-0,27$ & 0,23 & 0,80 & $-0,31$ & 0,10 & 0,12 \\
\hline MБP & $-0,16$ & 0,92 & $-0,02$ & 0,13 & 0,85 & 0,39 & $-0,12$ \\
\hline ШМББ & 0,59 & 0,61 & 0,04 & 0,31 & 0,24 & 0,80 & $-0,20$ \\
\hline ГMББ & 0,37 & $-0,54$ & $-0,08$ & 0,09 & $-0,29$ & 0,10 & 0,83 \\
\hline УХКГ & 0,16 & $-0,49$ & 0,56 & 0,10 & $-0,82$ & 0,03 & 0,02 \\
\hline $\mathrm{Ar}$ & 0,87 & $-0,16$ & $-0,12$ & 0,88 & $-0,17$ & $-0,02$ & $-0,04$ \\
\hline Дбб & 0,89 & $-0,20$ & $-0,15$ & 0,90 & $-0,22$ & 0,00 & $-0,06$ \\
\hline$\varnothing Д с$ & 0,37 & 0,39 & $-0,06$ & 0,41 & 0,25 & 0,56 & 0,02 \\
\hline УНД & 0,34 & $-0,91$ & 0,12 & 0,14 & $-0,94$ & $-0,17$ & 0,10 \\
\hline УСК & 0,37 & $-0,44$ & $-0,08$ & 0,09 & $-0,29$ & 0,10 & 0,26 \\
\hline ШДЭ & 0,23 & 0,77 & 0,03 & 0,75 & 0,33 & $-0,10$ & $-0,22$ \\
\hline ШЛокЯ & 0,77 & 0,03 & 0,34 & 0,85 & 0,03 & 0,11 & $-0,07$ \\
\hline ВЛокЯ & 0,49 & 0,51 & 0,07 & 0,31 & 0,24 & 0,24 & $-0,24$ \\
\hline ØГчкиВ & 0,91 & $-0,07$ & $-0,06$ & 0,90 & 0,00 & 0,19 & $-0,23$ \\
\hline ШГчки & 0,23 & 0,61 & 0,03 & 0,35 & 0,33 & $-0,20$ & $-0,10$ \\
\hline ВØЛГБ & 0,91 & $-0,07$ & $-0,06$ & 0,90 & 0,00 & 0,19 & $-0,23$ \\
\hline ШЛЧБ & 0,59 & 0,61 & 0,03 & 0,65 & 0,35 & $-0,23$ & $-0,10$ \\
\hline СØЛГБ & 0,86 & 0,30 & $-0,04$ & 0,75 & 0,18 & 0,08 & 0,14 \\
\hline ВØМГБ & 0,72 & 0,25 & $-0,01$ & 0,73 & 0,20 & $-0,05$ & 0,00 \\
\hline ШМЧБ & 0,74 & 0,35 & 0,01 & 0,74 & 0,23 & 0,15 & 0,02 \\
\hline СØМГБ & $-0,04$ & 0,22 & 0,70 & 0,29 & 0,14 & 0,12 & $-0,47$ \\
\hline ШМНM & 0,25 & 0,03 & 0,75 & 0,22 & 0,41 & 0,08 & 0,58 \\
\hline ШЛНМ & 0,75 & 0,00 & 0,38 & 0,74 & 0,16 & $-0,07$ & 0,54 \\
\hline УНББ & $-0,17$ & 0,55 & 0,22 & $-0,11$ & 0,20 & $-0,13$ & 0,32 \\
\hline Общая дисперсия & 6,72 & 4,05 & 1,18 & 7,19 & 3,29 & 1,41 & 1,47 \\
\hline $\begin{array}{c}\text { Выделенная } \\
\text { дисперсия }\end{array}$ & 0,37 & 0,22 & 0,06 & 0,39 & 0,18 & 0,07 & 0,08 \\
\hline
\end{tabular}

Примечание: $Ф 1^{*}$ - фрактор и его порядковый номер; статистически значимыми $Ф \mathrm{H}$ при $\mathrm{p} \geq 0,05$ являются нагрузки с силой равной |0,7-1,0|. Серым цветом выделены ячейки структур, имеющие ФН среди препаратов обеих групп.

Вторая группа параметров, выявленная в результате факторного анализа, отличалась присутствием статистически значимых ФН только в случае принадлежности кости к одной из сторон. Данную группу мы считаем системно нестабильными параметрами, указывающими на морфофункциональную асимметричность строения плечевой кости. В группе левой плечевой кости такими параметрами явились: сагиттальный размер головки, ширина и глубина межбугорковой борозды и угол хрящевого края головки; последний имел отрицательные $Ф$. Также как и у человека, в межбугорковой борозде плечевой кости быка проходит одна из головок m. biceps brachii, которая одновременно является сгибателем локтевого сустава, разгибателем плечевого и путового суставов, а при статической нагрузке фиксирует плечевой сустав [56]. Головка плечевой кости быка располагается ниже бугров, мест прикрепления мышц. Угол покрытия головки хрящом, отражающий площадь суставной поверхности и амплитуду движения в суставе, будет находиться под действием тяги двуглавой мышцы плеча, в результате чего данный параметр и испытывает отрицательные ФН при реализации движений в плечевом суставе. Системно нестабильными параметрами правой плечевой кости были сагиттальный диаметр медиального гребня блока и ширина медиального надмыщелка. Появление ФН у данных параметров в организации 
плечевой кости указывает на большую долю правой конечности животного в реализации двигательной фуннццй на уровне локтевого сустава.

При анализе структуры анатомической организации плечевой кости быка выделены 5 базовых системно стабильных параметров в структуре проксимального эпифиза, 3 - в структуре диафиза и 8 - в структуре дистального эпифиза. Нестабильных параметров на уровне проксимального эпифиза выделено 4, на уровне дистального - 2. Данные параметры указывают на асимметрию реализации двигательной функции на уровне эпифизов кости.

Заключение. Таким образом в результате проведенного исследования установлено, что для плечевой кости животного характерна латентная асимметрия, не выявляемая методами вариационной статистики. Ключевую роль в формировании системной организации плечевой кости играют базовые системно стабильные параметры, обеспечивающие трансляцию веса животного. Асимметрия системной структурной анатомической организации проявляется за счет разницы в реализации двигательной функции на уровнях эпифизов плечевой кости.

\section{Авторы заявляют об отсутствии каких бы то ни было конфликтов интересов.}

\section{ЛИТЕРАТУРА \\ REFERENCES}

1. Alexander RMcN. Allometry of the Limbs of Antelopes (Bovidae). J Zool (London). 1977:183:125-146.

2. Biewener AA. Allometry of quadrupedal locomotion: the scaling of duty factor, bone curvature and limb orientation to body size. $J$ Exp Biol. 1983;105:147-171.

3. Alexander RMcN. Principles of Animal Locomotion. Princeton, New Jersey: Princeton University Press, 2006.- 384pp.

4. Boelling D, Pollott GE. Locomotion, lameness, hoof and leg traits in cattle II: Genetic relationships and breeding values. Livestock Production Science. 1998;54(3):205-215.

5. Frandson RD, Fails AD, WL. Wilke Anatomy and Physiology of Farm Animals. Philadelphia, Pennsylvania: Lippincott Williams\&Wilkins Publishers, 2003.- 600pp.

6. Gambaryan PP. How Mammals Run. Anatomical Adaptations. Jerusalem: Keter Publishing House, 1974.- 368pp.

7. Yashina IN, Ivanov AV, Ivanov MA, Lvovsky AA, Samakha AA. On the issue of the system organization of tetrapod humerus. Kursk Scientific and Practical Bulletin «Human and His Health». 2018;(2):81-85.

\section{Авторская справка}

Яшина Ирина Николаевна, кандидат медицинских наук, доцент кафедры анатомии человека, Курский государственный медицинский университет, Курск, Россия; e-mail: bik2709@rambler.ru

Иванов Александр Викторович, доктор медицинских наук, профессор, заведующий кафедрой гистологии, эмбриологии и цитологии, человека, Курский государственный медицинский университет, Курск, Россия; e-mail: kstu-bmi@yandex.ru Клочкова Светлана Валерьевна, доктор медицинских наук, профессор кафедры анатомии человека, Первый Московский государственный медицинский университет имени И.М. Сеченова, Москва, Россия; e-mail: swetlana.chava@yandex.ru 